\title{
The Influence of Community Violence on the Functioning of Women Experiencing Domestic Violence
}

\author{
G. Anne Bogat, ${ }^{1,4}$ Kerry Leahy ${ }^{1}$ Alexander von Eye, ${ }^{1}$ Christopher Maxwell, ${ }^{2,3}$ \\ Alytia A. Levendosky, ${ }^{1}$ and William S. Davidson II $^{1}$
}

\begin{abstract}
The relationships among women's experiences of domestic violence, community violence, and their mental health functioning were explored $(N=94)$. Social contagion theory was used to argue for the link between community violence and family violence. Results revealed that women's experiences of domestic violence were not related to community violence. Furthermore, women's mental health functioning was solely associated with their experiences of domestic violence, not with community violence. Results are discussed in terms of an ecological model of domestic violence and future directions for exploring linkages between neighborhood characteristics and individual experiences.
\end{abstract}

KEY WORDS: domestic violence; community violence; social contagion theory; women's mental health.

\section{INTRODUCTION}

This study examined the effects of community violence on women's experiences of domestic violence (DV; defined here as male violence against their female romantic partners) and their mental health outcomes. DV has typically been studied from an individual perspective with a focus on qualities of an individual victim or perpetrator that predict risk for DV or the effects of DV. However, an ecological framework suggests that an individual is embedded within a community and that community factors may be relevant in understanding individual and family functioning (Bronfenbrenner, 1977; Cicchetti \& Lynch, 1993). Studies have linked sev-

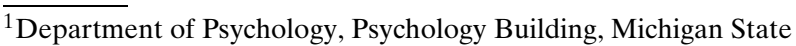
University, East Lansing, Michigan.

${ }^{2}$ School of Criminal Justice at Michigan State University, East Lansing, Michigan.

${ }^{3}$ Inter-University Consortium for Political and Social Research, University of Michigan, Ann Arbor, Michigan.

${ }^{4}$ To whom correspondence should be addressed at Department of Psychology, Psychology Building, Michigan State University, East Lansing, Ann Arbor, Michigan 48824-1116; e-mail: bogat@msu.edu.
}

eral structural characteristics of neighborhoods to violence within families (Coulton, Korbin, Su, \& Chow, 1995), among peers (Bursik \& Webb, 1982; Kupersmidt, Griesler, DeRosier, Patterson, \& Davis, 1995), and in the community (Morenoff \& Sampson, 1997). For example, O'Campo and colleagues (1995) used three census variables-home ownership, income, and unemployment - to predict women's risk for DV. Moreover, empirical research has linked community violence to family violence, including child maltreatment (Lynch \& Cicchetti, 1998) and interparental violence (Richters \& Martinez, 1993), and to men who perpetrate DV (Fagan, Stewart, \& Hansen, 1983). For example, Fagan et al. (1983) found that $46 \%$ of batterers had been previously arrested for other violent crimes and that the most violent batterers were those who were also violent toward strangers, suggesting that severity of DV is associated with perpetration of violence outside the home.

Social contagion theory suggests an explanation by which community violence and women's experiences of DV may be related (Anderson, 1990; Fagan, Wilkinson, \& Davies, 2000). The theory assumes that ideas, beliefs, and behaviors relevant to violence are 
transmitted through a social environment. It suggests that neighborhoods develop their own social norms for violence due to the domination of street codes of justice and social approval and rewards for violent behavior. The social norms developed in these neighborhoods may offer few alternative ways to resolve conflicts other than violence. Thus, the climate of fear that is present in some neighborhoods leads individuals to develop a code of toughness and promotes an ethos that encourages displays of violence.

Researchers have studied the social contagion of violence from a neighborhood-level perspective. Accordingly, the relationships among rates of various types of crime have been examined across people within neighborhoods. These types of studies suggest that violence behaves according to social contagion theory. For example, Rodgers and Rowe (1993) modeled ways in which rates of adolescent criminal behavior and delinquent activities spread through social networks. In addition, studies suggest that this contagion effect appears to cross types of violence. Baron, Murray, and Jaffee (1988) found a cultural spillover effect in communities from rates of legitimized violence to rape, and Koss and Cleveland (1997) argue that rape-supportive environments encourage aggressive male behavior. In other words, violence may act as a contagion in a community, spreading through a community and increasing the rates of violent crime, including violence against women. Thus, those women with personal experiences of DV are likely to live in violent communities. In this study, we hypothesize that both of these factors, the individual experience of DV and the violent crime in the neighborhood, will influence women's psychological functioning.

\section{Psychological Functioning}

Research on DV and its consequences for women's psychological functioning are welldocumented. As compared to nonvictimized women, victimized women experience increased levels of psychological distress, depression, anxiety, substance use, PTSD, and lower self-esteem (Bogat, Levendosky, Theran, von Eye, \& Davidson, 2003; Cascardi \& O'Leary, 1992; Houskamp \& Foy, 1991; Huth-Bocks, Levendosky, \& Bogat, 2002; Kessler, Molnar, Feurer, \& Appelbaum, 2001; Levendosky et al., in press; Vitanza, Vogel, \& Marshall, 1995).

The relationship between community violence and women's mental health is less clear. Holland
(1997), studying low-income mothers, found that both direct exposure to community violence and fear of victimization were associated with high levels of maternal depression. In a small sample, Aisenberg (2001) found that exposure to community violence was associated with high levels of depression, PTSD, and anxiety. Although few studies directly examine women's psychological responses to community violence, many studies with children suggest that community violence results in depression, anxiety, aggression, antisocial behavior, trauma symptoms, and increased fear (Dahlberg, 1998; Drell, Siegel, \& Gaensbauer, 1993; Farrell \& Bruce, 1997; GormanSmith \& Tolan, 1998; Kupersmidt et al., 1995; Lynch \& Cicchetti, 1998; Martinez \& Richters, 1993; McWhirter, 1983; Miller, Wasserman, Neugebauer, Gorman-Smith, \& Kamboukos, 1999; Osofsky \& Fenichel, 1994; Pynoos, 1993).

Despite the suggested links among community, family, and individual functioning, researchers in the area of DV have not yet examined the relationship between neighborhood-level crime, victims' experiences of DV, and mental health status, and researchers examining the relationship between community violence and violence in the family have not examined individual-level outcomes. This study conducted analyses to examine the relationship between women's exposure to community violence, her experience of domestic violence, and her mental health functioning. Our study expanded this area of research by integrating, through GIS technology, community-level data with individual-level data to determine whether community crime was predictive of individual mental health within a sample of women with different lifetime experiences and severities of DV victimization. This approach makes our study considerably different than most research examining the spatial location of social behavior. That research has been variable-oriented and has focused on defining community characteristics associated with particular crimes (e.g., DV, juvenile acts of delinquency). Our research is person-oriented and asks, using Configural Frequency Analysis (CFA; Lienert \& Krauth, 1975; von Eye, 2002), whether the number of participants who evince particular patterns of DV, Community Violence, and Women's Mental Health occur more or less likely than chance. This analysis assumes that the relationships among the variables are not uniform across all the variable values. Thus, the configurations that result describe groups of individuals, not scores on the variables. 


\section{METHODS}

\section{Participants}

Participants were 94 women, a subsample of the 206 women in a longitudinal investigation examining risk and resilience factors for DV, conducted by the first, third, fifth, and sixth authors (Bogat, Levendosky, \& Davidson, 1999; Levendosky, Bogat, Davidson, \& von Eye, 2000). The original sample of 206 was recruited in the community at various sites frequented by women such as ob/gyn offices and programs geared specifically for women and children (e.g., WIC). The sample was chosen to represent a wide range of experiences of DV ranging from none to severe. To participate, women had to be interviewed during their last trimester of pregnancy, they had to speak sufficient English to answer questionnaires, and they had to be between the ages of 18 and 40.

The subsample of 94 women in this study was selected because they lived in the Midwestern city for which we had officially recorded police crime data. We did not have crime data for the communities in which the other women lived. These 94 women identified themselves as $46 \%$ Caucasian, $38 \%$ African American, 9\% Latina, and 7\% other ethnic/racial backgrounds. The majority of women had a high school education or less $(45 \%)$. Over half of the women were single/never married, $35 \%$ were married, and $13 \%$ were separated, divorced, or widowed. Monthly income for the women ranged from \$267 to $\$ 7,000$, with a median monthly income of $\$ 1,350$.

\section{Procedures}

The community-level data were obtained as follows. Two types of shapefiles were created, allowing multiple sets of data to be layered and spatially joined. First, target metropolitan area jurisdiction and census block group shapefiles were obtained. Second, participant residence addresses at the time of their respective interview dates were digitally geocoded to create another shapefile. Using the census map of the target Midwestern city, participants were assigned a neighborhood based on the block group in which the participant lived. Although most researchers define neighborhoods as census tracts (e.g., Coulton et al., 1995; Ernst, 2000; MilesDoan, 1998; Queralt \& Witte, 1998), critics suggest that census tracts are too socially disjointed and het- erogeneous to represent a reasonable approximation of a neighborhood (Tienda, 1991). Thus, we chose census block groups, a smaller spatial unit equivalent to about four city blocks as a more realistic estimate of naturally occurring neighborhoods. Names of victims and offenders were removed and the last two digits of the building number were removed to protect household confidentiality.

ArcGIS matching preferences were set at 100 to ascertain accuracy of the geocoding process for participant addresses. All nonmatched addresses were manually checked and geocoded as necessary. Procedures were taken to assure that the layers of geographic data occupied the same space, thereby allowing the relationships among the various data sets to be studied.

The mental health and DV data analyzed here is only a sample of the information we obtained from these women during the interview that occurred at the time of the infant's first birthday. Women came to project offices for the interview and gave their informed consent prior to data collection. An ethnically diverse group of female, undergraduate research assistants were trained by project staff to collect the data. They also met for weekly supervision. Research assistants were blind to the hypotheses of the study and the battering status of the women (questionnaires referring to DV were administered near the end of the assessment protocol). Women were reimbursed for their participation and given a list of community resources.

\section{Measures}

\section{Community Violence}

Two measures of community violence were used: police incident reports of aggravated assault and disorderly conduct offenses. The following definitions, used by the state in which the study took place, were used, "Aggravated assault is an unlawful attack by one person upon another for the purpose of inflicting severe or aggravated bodily harm. This type of assault is usually accompanied by the use of a weapon or by means likely to produce death or great bodily harm" and disorderly conduct is "an offense which disturbs the peace and tranquility of the community in general." (We did not have access to homicide and sexual assault crime data because it was removed by the police department to protect the confidentiality of the victims.) Incidents of these two 
crimes were geocoded and aggregated at the block group level to correspond to neighborhoods. Participants were assigned a score for each type of crime based on the number of crimes that occurred during the previous year in the census block group where the participant resided. Such a time frame was employed because (a) many of our women were mobile and likely to eventually move into different neighborhoods, and we did not want too much time to elapse between the assessment of DV and mental health and the times at which the crimes occurred and (b) the level of crime in the target Midwestern city was not extremely high, 1 year represented a reasonable period in which to capture sufficient crime data.

\section{Demographics}

A brief questionnaire was administered to obtain basic demographic information including age, ethnicity, religion, family composition, marital or relationship status, domicile history, education level, occupation, and family income.

\section{Domestic Violence}

Domestic violence was measured with the Severity of Violence Against Women Scales (SVAWS), a 46-item instrument assessing threats of violence, actual physical violence, and sexual violence along a continuum ranging from none to severe (Marshall, 1992). Example items include, "Hit or kicked a wall, door, or furniture," "Threatened to hurt you," "Pushed or shoved you," "Beat you up," and "Physically forced you to have sex." Women rated their experiences of abuse for each romantic relationship (lasting at least 6 weeks) during the past year on a 4-point scale with response choices ranging from never to many times. A composite score was calculated by summing the item scores. Possible scores for any single partner range from 0 to 138 with higher scores indicating more abuse. Marshall reported coefficient alphas among a community sample ranging from a low of .89 for symbolic violence to a high of .96 for both mild and serious physical violence.

\section{Mental Health}

Posttraumatic stress symptomatology was assessed using the Posttraumatic Stress Scale for
Family Violence, a 17-item questionnaire developed to assess posttrauma pathology in battered women (Saunders, 1994). On the basis of the DSM III-R criteria for Posttraumatic Stress Disorder, the questionnaire measures three types of symptoms (1) avoidance of stimuli (e.g., "Trying to avoid thoughts or feelings associated with the behaviors"), (2) intrusive re-experiencing (e.g., "Unpleasant memories of the behaviors you can't keep out of your mind"), and (3) increased arousal (e.g., "Very easily startled"). Women rated the presence of symptoms experienced as a result of domestic violence on an 8-point scale with response options ranging from never to over 100 . (By definition, participants not experiencing DV received a 0 on this scale.) Participants received a continuous score reflecting posttraumatic stress symptom severity, calculated by summing the answers on the original 17 items. Possible scores range from 0 to 119 , with higher scores suggesting more PTSD symptomatology. Saunders (1994) reported a coefficient alpha of .94 , indicating satisfactory internal consistency reliability.

Anxiety was measured with the 6-item anxiety dimension of the Brief Symptom Inventory (BSI), a brief psychological self-report symptom inventory that evolved from its parent instrument, the SCL-90R (Derogatis \& Melisaratos, 1983). Example items include, "Nervousness or shakiness inside," "Feeling fearful," and "Feeling so restless you can't sit still." Participants rated how much they were distressed by each symptom during the previous week on a 5-point scale ranging from not at all to extremely. A total anxiety score was obtained by summing the answers on all six items. Possible scores range from 0 to 24. Derogatis and Melisaratos reported an alpha of .81 and test-retest reliability of .79 .

Depression was assessed using the 21-item Beck Depression Inventory (BDI; Beck, Ward, Mendelson, Mock, \& Erbaugh, 1961). The instrument covers a wide variety of symptoms of depression, including depressed mood, sense of failure, social withdrawal, self-loathing, and sleep and eating disturbances. Each of the 21 symptom categories consists of four or five evaluative statements ranked in order of severity from neutral to severe. For example, the first symptom category, depressed mood, consists of the following four statements: "I do not feel sad," "I feel sad," "I am sad all the time and I can't snap out of it," and "I am so sad or unhappy that I can't stand it." Each woman chose the statement from each grouping that best described how she had been feeling during the course of 
Table I. Descriptive Data for Predictors and Outcomes $(N=94)$

\begin{tabular}{lrrc}
\hline \multicolumn{1}{c}{ Variable } & Mean & \multicolumn{1}{c}{$S D$} & Range \\
\hline Aggravated assault & 8.80 & 6.89 & $0-23$ \\
Disorderly conduct & 13.39 & 11.24 & $1-53$ \\
Domestic violence & 5.14 & 11.58 & $0-59$ \\
Trauma symptoms & 4.94 & 12.16 & $0-57$ \\
Anxiety & 2.38 & 2.95 & $0-12$ \\
Depression & 6.35 & 5.84 & $0-29$ \\
\hline
\end{tabular}

the previous week. A total depression score was obtained by summing the 21 item answers. Possible scores range from 0 to 63 , higher scores indicating more depression. Beck et al. (1961) reported a split-half reliability of .93 after a Spearman-Brown correction. Lightfoot and Oliver (1985) reported a test-retest reliability of .90 over a 2 -week interval.

\section{RESULTS}

Table I contains descriptive information about the variables used in the analyses. Also, the rates of aggravated assault for our study city are higher than the average of 14 cities of comparable population in the State (see Table II). In fact, our study city has rates of disorderly conduct and assault that are among the highest in the State. However, compared to large, metropolitan areas such as New York City or Dallas, the numbers of these crimes are modest.

Configural Frequency Analysis (CFA) was used to determine the statistical likelihood of occurrence for patterns involving community violence, DV, and mental health outcomes. CFA configurations result from crossing categorical or categorized variables. CFA types are constituted by patterns that are ob-

Table II. Number of Aggravated Assault Offenses in 1999 for Participant Neighborhoods, Study City, and Comparison Cities ${ }^{a}$

\begin{tabular}{lc}
\hline & $\begin{array}{c}\text { Number of aggravated } \\
\text { assault offenses }\end{array}$ \\
\hline Participant neighborhoods $(n=49)$ & $348(x=7.10)$ \\
Study city & 741 \\
Average of 14 comparable-sized & 276 (range: 4-1982) \\
$\quad$ cities in same state & \\
New York & 34449 \\
Dallas & 7365 \\
\hline
\end{tabular}

${ }^{a}$ The FBI's Uniform Crime Reporting program does not collect offense counts for crimes that make up our "disorderly conduct" measure.

${ }^{b}$ U.S. Department of Justice, Federal Bureau of Investigation (1999). Uniform Crime Reporting Program Data: Offenses Known and Clearances by Arrest. [computer file] ICPSR ed. Ann Arbor, MI: ICPSR, 2001. served significantly more often than expected; CFA antitypes are constituted by patterns that are observed significantly less often than expected. Those cells that are observed about as often as expected do not constitute either a CFA type or antitype. In any data analysis, it is typical that all three possibilities will result.

CFA configurations are based on creating dichotomous categories for each variable. In the present analyses, each variable was split into "high" and "low" scores. The community violence variables (aggravated assault and disorderly conduct) were normally distributed and, thus, were split on the median. The mental health and DV variable distributions were skewed, with large numbers of "0" values; therefore, the scores were cut at zero. Three separate CFAs were run for each mental health variable. Each included four variables: the two indicators of community violence, one indicator of $\mathrm{DV}$, and one indicator of mental health (depression, anxiety, or trauma symptoms). Thus, for each CFA, 16 configurations or patterns were possible. Because of the large number of significance tests on the same data, CFA creates an increased risk of capitalizing on chance. Therefore, Bonferroni's method is typically used, and was used here, to protect the significance threshold $\alpha$. Lehmachers test was used with a Bonferroni-adjusted alpha of .0031250 .

Six patterns or configurations occurred significantly more often than expected for these women (CFA Types; see Table III for summary of CFA Types). Women whose profiles were characterized by low levels of community violence (both aggravated assault and disorderly conduct) and no DV exhibited no trauma symptoms. This type occurred approximately two times more often than would be expected (see Table III for patterns of exposure to violence in relation to trauma symptoms). Women whose profiles were characterized by low levels of community violence (both aggravated assault and disorderly conduct) and some DV had some trauma symptoms,

Table III. Summary of CFA Types

\begin{tabular}{lccl}
\hline \multicolumn{3}{c}{ Configuration } \\
\hline $\begin{array}{l}\text { Aggravated } \\
\text { assault }\end{array}$ & $\begin{array}{c}\text { Disorderly } \\
\text { conduct }\end{array}$ & DV & $\begin{array}{c}\text { Mental } \\
\text { health symptoms }\end{array}$ \\
\hline Low & Low & None & No trauma \\
Low & Low & Some & Some trauma \\
Low & Low & Some & Some anxiety \\
Low & Low & Some & Some depression \\
High & High & None & No trauma \\
High & High & None & No anxiety \\
\hline
\end{tabular}


Table IV. Results of CFA for Aggravated Assault, Disorderly Conduct, Domestic Violence, and Trauma Symptoms ${ }^{a}$

\begin{tabular}{ccccrcl}
\hline Configuration & Observed & Exp. & Ratio O/E & Statistic & $p$ & \\
\hline 1111 & 18 & 8.669 & 2.076 & 4.072 & .00002332 & Type \\
1112 & 1 & 4.063 & 0.246 & -1.760 & .03919047 & \\
1121 & 4 & 7.628 & 0.524 & -1.651 & .04933006 & \\
1122 & 13 & 3.576 & 3.636 & 5.692 & .00000001 & Type \\
1211 & 7 & 9.439 & 0.742 & -1.036 & .15014810 & \\
1212 & 0 & 4.425 & 0.000 & -2.461 & .00692628 & \\
1221 & 1 & 8.306 & 0.120 & -3.233 & .00061255 & Antitype \\
1222 & 6 & 3.894 & 1.541 & 1.230 & .10927215 & \\
2111 & 4 & 7.628 & 0.524 & -1.651 & .04933006 & \\
2112 & 0 & 3.576 & 0.000 & -2.160 & .01539972 & \\
2121 & 2 & 6.713 & 0.298 & -2.241 & .01252744 & \\
2122 & 3 & 3.147 & 0.953 & -0.093 & .46285119 & \\
2211 & 19 & 8.306 & 2.287 & 4.732 & .00000111 & Type \\
2212 & 1 & 3.894 & 0.257 & -1.690 & .04548543 & \\
2221 & 9 & 7.310 & 1.231 & 0.780 & .21755526 & \\
2222 & 6 & 3.426 & 1.751 & 1.581 & .05694767 & \\
\hline
\end{tabular}

Note. $\chi^{2}$ for CFA model $=78.3977 ; d f=11 ; p=.00000000 ;$ LR- $\chi^{2}$ for CFA model $=77.5601$; $d f=11 ; p=.00000000$.

${ }^{a}$ The CFA tables are read as follows. $1=$ low and $2=$ high for crime variables; $1=$ none and $2=$ some for domestic violence and mental health variables. The order of the variables in any given configuration correspond to the order in the table title. For example, in this table, 1111 represents 18 women who all had low scores for assault and disorderly conduct as well as no domestic violence and no trauma symptoms.

anxiety, and depressive symptoms (see Tables IV, V, and VI). For trauma symptoms, this pattern emerged almost four times more often than expected. Finally, those women whose profiles were characterized by high levels of community violence (both assault and disorderly conduct) and no DV exhibited no trauma or anxiety symptoms (see Tables III and V, respectively). This configuration occurred over two times more often than would be expected when trauma symptoms were the mental health outcome.

Findings also revealed three patterns or configurations that occurred significantly less often than

Table V. CFA Results for Aggravated Assault, Disorderly Conduct, Domestic Violence, and Depressive Symptoms

\begin{tabular}{crrrrrl}
\hline Configuration & Observed & \multicolumn{1}{c}{ Exp } & Ratio O/E & Statistic & $p$ & \\
\hline 1111 & 4 & 1.490 & 2.685 & 2.266 & .01172235 & \\
1112 & 15 & 11.242 & 1.334 & 1.543 & .06144268 & \\
1121 & 0 & 1.311 & 0.000 & -1.248 & .10596606 & \\
1122 & 17 & 9.893 & 1.718 & 3.025 & .00124455 & Type \\
1211 & 0 & 1.622 & 0.000 & -1.415 & .07855598 & \\
1212 & 7 & 12.241 & 0.572 & -2.103 & .01774254 & \\
1221 & 0 & 1.428 & 0.000 & -1.312 & .09479873 & \\
1222 & 7 & 10.772 & 0.650 & -1.567 & .05853336 & \\
2111 & 1 & 1.311 & 0.763 & -0.296 & .38353479 & \\
2112 & 3 & 9.893 & 0.303 & -2.934 & .00167515 & Antitype \\
2121 & 1 & 1.154 & 0.867 & -0.155 & .43856809 & \\
2122 & 4 & 8.706 & 0.459 & -2.080 & .01876219 & \\
2211 & 3 & 1.428 & 2.101 & 1.445 & .07427290 & \\
2212 & 17 & 10.772 & 1.578 & 2.587 & .00483841 & \\
2221 & 2 & 1.256 & 1.592 & 0.721 & .23549247 & \\
2222 & 13 & 9.480 & 1.371 & 1.517 & .06463770 & \\
\hline
\end{tabular}

Note. $\chi^{2}$ for CFA model $=33.0369 ; d f=11 ; p=.00051896 ;$ LR- $\chi^{2}$ for CFA model $=36.9279$; $d f=11 ; p=.00011848$. 
Table VI. CFA results for Aggravated Assault, Disorderly Conduct, Domestic Violence, and Anxiety

\begin{tabular}{ccccrcl}
\hline Configuration & Observed & Exp & Ratio O/E & Statistic & $p$ & \\
\hline 1111 & 9 & 4.605 & 1.954 & 2.399 & .00823025 & \\
1112 & 10 & 8.127 & 1.230 & 0.833 & .20242186 & \\
1121 & 3 & 4.053 & 0.740 & -0.603 & .27312880 & \\
1122 & 14 & 7.152 & 1.958 & 3.180 & .00073686 & Type \\
1211 & 2 & 5.015 & 0.399 & -1.594 & .05552380 & \\
1212 & 5 & 8.849 & 0.565 & -1.665 & .04800388 & \\
1221 & 2 & 4.413 & 0.453 & -1.338 & .09038183 & \\
1222 & 5 & 7.787 & 0.642 & -1.257 & .10431939 & \\
2111 & 3 & 4.053 & 0.740 & -0.603 & .27312880 & \\
2112 & 1 & 7.152 & 0.140 & -2.856 & .00214316 & Antitype \\
2121 & 0 & 3.566 & 0.000 & -2.150 & .01577723 & \\
2122 & 5 & 6.293 & 0.794 & -0.628 & .26501663 & \\
2211 & 10 & 4.413 & 2.266 & 3.099 & .00097001 & Type \\
2212 & 10 & 7.787 & 1.284 & 0.998 & .15910840 & \\
2221 & 5 & 3.883 & 1.288 & 0.651 & .25754347 & \\
2222 & 10 & 6.853 & 1.459 & 1.483 & .06903657 & \\
\hline
\end{tabular}

Note. $\chi^{2}$ for CFA model $=36.1270 ; d f=11 ; p=.00016120 ;$ LR $-\chi^{2}$ for CFA model $=$ $39.6409 ; d f=11 ; p=.00004120$.

expected for these women (CFA Antitypes; see Table VII for a summary of CFA Antitypes). The following patterns are therefore highly unlikely. Women whose profiles were characterized by low levels of assault, high levels of disorderly conduct, and some DV had no trauma symptoms, a pattern that emerged in about $10 \%$ of the expected rate. Women whose profiles were characterized by high levels of assault, low levels of disorderly conduct, and no DV exhibited some depressive symptoms. Finally, women whose profiles were characterized by high levels of assault, low levels of disorderly conduct, and no DV exhibited some anxiety.

\section{DISCUSSION}

This study examined individual patterns of exposure to community violence and in relation to mental health outcomes. The results revealed that the women in our sample could be characterized by six CFA types and three antitypes. Although

Table VII. Summary of CFA Antitypes

\begin{tabular}{lccl}
\hline \multicolumn{3}{c}{ Configuration } \\
\hline $\begin{array}{l}\text { Aggravated } \\
\text { assault }\end{array}$ & $\begin{array}{c}\text { Disorderly } \\
\text { conduct }\end{array}$ & DV & $\begin{array}{c}\text { Mental } \\
\text { health symptoms }\end{array}$ \\
\hline Low & High & Some & No trauma \\
High & Low & None & Some depression \\
High & Low & None & Some anxiety \\
\hline
\end{tabular}

individual types and antitypes can be interpreted, the results are stronger if patterns of findings emerge. Our results indicate that, overall, women who experience no DV will show no mental health problems, regardless of level of community violence. Social contagion theory would suggest that levels of community violence and experiences of DV should be positively related to one another, but the CFA types did not find this pattern. Similarly, contrary to ecological theory, women's experiences of community violence were not predictive of their mental health outcomes. When community violence levels were high and the women had not experienced DV, they also had no trauma or anxiety symptoms. In contrast, patterns of individual DV experienced by women were consistently related to their mental health outcomes. Regardless of community violence scores, no experiences of DV predicted no mental health problems, whereas experiences of DV were related to some trauma and anxiety symptoms. Thus, even at high levels of community violence, it appears that, in our study, only the experience of some DV predicted some mental health problems.

Our finding, that there was a relationship between DV and women's psychological functioning, is consistent with the large number of studies that document poor mental health outcomes for battered women, including elevated levels of depression, anxiety, posttraumatic stress disorder, and suicidal behavior and completion (e.g., Cascardi \& O'Leary, 1992; Dutton \& Painter, 1993; Fagan \& Browne, 
1994; Magdol, Moffitt, Caspi, \& Silva, 1998; Magdol et al., 1997; Stark \& Flitcraft, 1996; Thompson et al., 2000; Vitanza et al., 1995).

The social contagion theory of violence was not supported; in this research, community violence was not consistently related to women's personal experiences of DV or their mental health functioning. Social contagion theory was originally developed and empirically supported on the basis of data from large cities, such as New York City, that are characterized by high levels of criminal activity (Fagan, Wilkinson, \& Davies, 2000). It is possible that social contagion theory is not applicable to mid-size communities with relatively low levels of community violence. Alternatively, it is possible that other types of violent crime, not investigated here, such as homicide, robbery, criminal sexual conduct, shots-fired, and burglary, which are likely to create "fear of crime" in community residents (see Ross \& Jang, 2000; Rountree, 1998) may be related to DV and personal mental health. Furthermore, social contagion theory has been tested and supported only when examining relationships between different crimes measured at the community- or neighborhood-level. We attempted to extrapolate this theory to encompass neighborhoodand individual-level data. Our findings indicate, however, that this extension may not be valid. There may not be a relationship between a woman's personal experiences of DV and the aggravated assault and disorderly conduct crimes occurring in the neighborhood where she lives.

Alternatively, a relationship between individual variables and community violence might only be present in those communities in which high levels of community crime occur. For example, research finds that it is more difficult for families living in areas of high risk (including high levels of violent crime), as compared to those living in areas of low risk, to mediate the effects of these environments on problematic youth behavior, including aggression (e.g., Attar, Guerra, \& Tolan, 1994; GormanSmith \& Tolan, 1998; Mason, Cauce, Gonzales, \& Hiraga, 1996; Sheidow, Gorman-Smith, Tolan, \& Henry, 2001).

Finally, there were three antitypes, all distinguished by the fact that assault and disorderly conduct were at different levels-one high and the other low. These antitypes suggest that it is unlikely that assault and disorderly conduct are not related to each other in individual communities.

The current investigation had several strengths, including a diverse, community sample of women with a range of DV experiences, the use of census block groups to define neighborhoods, the integration of individual- and neighborhood-level data to study the effects of DV, and the use of a personoriented data analysis strategy. The study, however, had some limitations. First, the small participant sample size may have precluded findings of positive associations between community violence and DV and community violence and mental health. Second, participant crime scores were not independent as many of our women lived in the same neighborhoods. Third, the study only assessed two types of community crime, aggravated assault, and disorderly conduct. Unfortunately, the authors did not have access to other violent crimes against persons, specifically homicide and criminal sexual conduct, which may have had a significant impact on family (perpetration of DV) and individual mental health functioning. Finally, and in addition, police records of neighborhood crime may not reflect what women perceive as the severity, quality, and quantity of violence in their communities.

This study was an initial attempt at integrating individual- and neighborhood-level data in the context of women's personal experiences of DV and their mental health outcomes. Findings indicated that, at least for this sample of women, who lived in communities with a relatively low amount of crime, community violence was not predictive of their experiences of DV or individual psychological functioning. Rather, DV was related to personal mental health regardless of levels of community violence. These results are preliminary. Additional, ecologically informed research is needed with larger samples and larger communities to further explore whether community violence is associated with women's experiences of DV and their mental health. The inclusion of other relevant variables such as personal demographics, women's perceptions of violence in their communities, and neighborhood structural characteristics may also provide insight into the causes and consequences of DV.

\section{ACKNOWLEDGMENT}

This study was supported, in part, by grants from the National Institute of Justice (\#87958-MI-IJ) and Centers for Disease Control (R01/CCR518519-03-1). Portions of this paper were presented at the Wellesley Centers for Women 2004 International Research and Action Conference: 


\author{
Innovations in Understanding Violence Against \\ Women, Wellesley, MA.
}

\section{REFERENCES}

Aisenberg, E. (2001). The effects of exposure to community violence upon Latina mothers and preschool children. Hispanic Journal of Behavioral Sciences, 23, 378-398.

Anderson, E. (1990). Streetwise: Race, class, and change in an urban community. Chicago: University of Chicago Press.

Attar, B., Guerra, N., \& Tolan, P. H. (1994). Neighborhood disadvantage, stressful life events, and adjustment in urban elementary-school children. Journal of Clinical Child Psychology, 23, 391-400.

Baron, L. S., Murray, A., \& Jaffee, D. (1988). Legitimate violence, violent attitudes, and rape: A test of the cultural spillover theory. Annals of the New York Academy of Sciences, 528, 79110.

Beck, A. T., Ward, C. H., Mendelson, M., Mock, J., Erbaugh, J. (1961). An inventory for measuring depression. Archives of General Psychiatry, 4, 561-571.

Bogat, G. A., Levendosky, A. A., \& Davidson, W. S. (1999). Understanding the intergenerational transmission of violence: From pregnancy through the first year of life. Grant from the National Institutes of Justice.

Bogat, G. A., Levendosky, A. A., Theran, S., von Eye, A., \& Davidson, W. S. (2003). Predicting the psychosocial effects of interpersonal partner violence (IPV): How much does a woman's history of IPV matter? Journal of Interpersonal Violence, 18, 121-142.

Bronfenbrenner, U. (1977). Toward an experimental ecology of human development. American Psychologist, 32, 513-531.

Bursik, R. J., \& Webb, J. (1982). Community change and patterns of delinquency. American Journal of Sociology, 88, 24-42.

Cascardi, M., \& O'Leary, K. D. (1992). Depressive symptomatology, self-esteem, self-blame in battered women. Journal of Family Violence, 7(4), 249-259.

Cicchetti, D., \& Lynch, M. (1993) Toward an ecologi$\mathrm{cal} /$ transactional model of community violence and child maltreatment: Consequences for children's development. Psychiatry: Interpersonal and Biological Processes, 56(1), 96-11.

Coulton, C. J., Korbin, J. E., Su, M., \& Chow, J. (1995). Community level factors and child maltreatment rates. Child Development, 66, 1262-1276.

Dahlberg, L. (1998). Youth violence in the United States: Major trends, risk factors, and prevention approaches. American Journal of Preventative Medicine, 14, 259-272.

Derogatis, L. R., \& Melisaratos, N. (1983). The Brief Symptom Inventory: An introductory report. Psychological Medicine, 13, 595-605.

Drell, M., Siegel, C., \& Gaensbauer, T. (1993). Post-traumatic stress disorders. In C. Zeanah (Ed.), Handbook of infant mental health (pp. 291-304). New York: Guilford.

Dutton, D. G., \& Painter, S. (1993). The battered woman syndrome: Effects of severity and intermittency of abuse. American Journal of Orthopsychiatry, 63, 614-622.

Ernst, J. S. (2000). Mapping child maltreatment: Looking at neighborhoods in a suburban county. Child Welfare, 79(5), 555-572.

Fagan, J., \& Browne, A. (1994). Violence between spouses and intimates. In A. Reiss \& J. Roth (Eds.), Understanding and preventing violence (Vol. 3, pp. 115-292). Washington, DC: National Academy Press.

Fagan, J., Stewart, D. K., \& Hansen, K. V. (1983). Violent men or violent husbands? Background factors and situational correlates. In D. Finkelhor, R. Gelles, G. Hotaling, \& M. A. Strauss
(Eds.), The dark side of families: Current family violence research. Beverly Hills, CA: Sage.

Fagan, W., Wilkinson, D., \& Davies, G. (2000). Social contagion of youth homicide in New York. Paper presented at the Urban Seminar on Youth Violence in Urban Communities Boston, MA: Harvard University John F. Kenedy School of Government.

Farrell, A. D., \& Bruce, S. E. (1997). Impact of exposure to community violence on violent behavior and emotional distress among urban adolescents. Journal of Clinical Child Psychology, 26, 2-14.

Gorman-Smith, D., \& Tolan, P. (1998). The role of exposure to community violence and developmental problems among inner-city youth. Developmental Psychopathology, 10, 101116.

Holland, C. C. (1997). Homelessness and exposure to community violence: Exploration of maternal and child adjustment among low income families in head start. (Doctoral dissertation, University of Maryland, 1996). Dissertation Abstracts International, 57, 4710.

Houskamp, B. M., \& Foy, D. W. (1991). The assessment of posttraumatic stress disorder in battered women. Journal of Interpersonal Violence, 6, 367-375.

Huth-Bocks, A.C., Levendosky, A. A., \& Bogat, G. A. (2002). The effects of domestic violence during pregnancy on maternal and infant health. Violence and Victims, 8, 1-17.

Kessler, R. C., Molnar, B. E., Feurer, I. D., \& Appelbaum, M. (2001). Patterns and mental health predictors of domestic violence in the United States: Results from the National Comorbidity Survey. International Journal of Law and Psychiatry, $24,487-508$.

Koss, M. P., \& Cleveland, H. H. (1997). Stepping on toes: Social roots of date rape lead to intractability and politicization. In M. D. Schwartz (Ed.), Researching sexual violence against women: Methodological and personal perspectives (pp. 4-21). Thousand Oaks, CA: Sage.

Kupersmidt, J. B., Griesler, P. C., DeRosier, M. E., Patterson, C. J., \& Davis, P. W. (1995). Childhood aggression and peer relations in the context of family and neighborhood factors. Child Development, 66, 360-375.

Levendosky, A. A., Bogat, G. A., Davidson, W. S., \& von Eye, A. (2000). Risk and protective factors for domestic violence. Grant from Centers for Disease Control, Injury Prevention Center.

Levendosky, A. A., Bogat, G. A., Theran, S. A., Trotter, J. S., von Eye, A., \& Davidson, W. S. (2004). The social networks of women experiencing domestic violence. American Journal of Community Psychology, 34, 95109.

Lienert, G. A., \& Krauth, J. (1975). Configural Frequency Analysis as a statistical tool for defining types. Educational and Psychological Measurement, 35, 231-238.

Lightfoot, S. L., \& Oliver, J. M. (1985). The Beck Inventory: Psychometric properties in university students. Journal of Personality Assessment, 49(4), 434-436.

Lynch, M., \& Cicchetti, D. (1998). An ecological-transactional analysis of children and contexts: The longitudinal interplay among child maltreatment, community violence, and children's symptomatology. Development and Psychopathology, 10, 235-257.

Magdol, L., Moffitt, T. E., Caspi, A., \& Silva, P. A. (1998). Developmental antecedents of partner abuse: A prospectivelongitudinal study. Journal of Abnormal Psychology, 107, 375-389.

Magdol, L., Moffitt, T. E., Caspi, A., Newman, D., Fagan, J., \& Silva, P. A. (1997). Gender differences in partner violence in a birth cohort of 21-year-olds: Bridging the gap between clinical and epidemiological approaches. Journal of Consulting and Clinical Psychology, 65, 68-78. 
Marshall, L. L. (1992). Development of the Severity of Violence Against Women Scales. Journal of Family Violence, 7(2), 103121.

Martinez, P., \& Richters, J. E. (1993). The NIMH Community Violence Project: II. Children's distress symptoms associated with violence exposure. Psychiatry, 56, 22-35.

Mason, C. A., Cauce, A. M., Gonzales, N., \& Hiraga, Y. (1996). Neither too sweet nor too sour: problem peers, maternal control, and problem behavior in African American adolescents. Child Development, 67, 2115-2130.

McWhirter, L. (1983). Growing up in Northern Ireland: From "aggression" to the "troubles." In A. P. Goldstein \& M. H. Segall (Eds.), Aggression in global perspective (pp. 367-400). New York: Pergamon Press.

Miles-Doan, R. (1998). Violence between spouses and intimates: Does neighborhood context matter? Social Forces, 77(2), 623-645.

Miller, L. S., Wasserman, G. A., Neugebauer, R., Gorman-Smith, D., \& Kamboukos, D. (1999). Witnessed community violence and antisocial behavior in high-risk-urban boys. Journal of Clinical Child Psychology, 28, 2-11.

Morenoff, J., \& Sampson, R. J. (1997). Violent crime and the spatial dynamics of neighborhood transition: Chicago, 19701990. Social Forces, 76(1), 31-64.

O'Campo, P., Gielen, A. C., Faden, R. R., Xue, X., Kass, N., \& Wang, M. C. (1995). Violence by male partners against women during the childbearing year: A contextual analysis. American Journal of Public Health, 85(8 Pt 1), 10921097.

Osofsky, J. D., \& Fenichel, E. (1994). Caring for infants and toddlers in violent environments: Hurt, healing, and hope. Arlington, VA: Zero to Three/National Center for Clinical Infant Programs.

Pynoos, R. S. (1993). Traumatic stress and developmental psychopathology in children and adolescents. In J. M. Oldham, M. B. Riba, \& A. Tasman (Eds.), American Psychiatric Press Review of Psychiatry (Vol. 12). Washington, DC: American Psychiatric Press.
Queralt, M., \& Witte, A. D. (1998). A map for you? Geographic information systems in the social services. Social Work, 43(5), 455-469.

Richters, J., \& Martinez, P. (1993). The NIMH Community Violence Project: I. Children as victims of and witnesses to violence. Psychiatry, 56, 7-21.

Rodgers, J. L., \& Rowe, D. C. (1993). Social contagion and adolescent sexual behavior: A developmental EMOSA model. Psychological Review, 100, 479-510.

Ross, C. E., \& Jang, S. J. (2000). Neighborhood disorder, fear, and mistrust: The buffering role of social ties with neighbors. American Journal of Community Psychology, 28, 401-420.

Rountree, P. W. (1998). A reexamination of the crime-fear linkage. Journal of Research $n$ Crime and Delinquency, 35(3), 341-372.

Saunders, D. G. (1994). Posttraumatic stress symptom profiles of battered women: A comparison of survivors in two settings. Violence and Victims, 9(1), 31-44.

Sheidow, A. J., Gorman-Smith, D., Tolan, P. H., \& Henry, D. B. (2001). Family and community characteristics: Risk factors for violence exposure in inner-city youth. Journal of Community Psychology, 29(3), 345-360.

Stark, E., \& Flitcraft, A. (1996). Women at risk: Domestic violence and women's health. Thousand Oaks, CA: Sage.

Thompson, M. P., Kaslow, N. J., Kingree, J. P., Rashid, A., Puett, R., Jacobs, D., \& Matthews, A. (2000). Partner violence, social support, and distress among inner-city African American women. American Journal of Community Psychology, 28(1), 127-143.

Tienda, M. (1991). Poor people and poor places: Deciphering neighborhood effects on poverty outcomes. In J. Huber (Ed.), Macro-micro linkages in sociology (pp. 244-262). Thousand Oaks, CA: Sage.

Vitanza, S., Vogel, L. C. M., \& Marshall, L. L. (1995). Distress and symptoms of posttraumatic stress disorder in abused women. Violence and Victims, 10(1), 23-34.

von Eye, A. (2002). Configural frequency analysis: Methods, models, and applications. New Jersey: Erlbaum. 